\title{
Gentrificación rururbana. Estudios territoriales en La Florida (Manizales- Villamaría) y Cerritos (Pereira) Colombia
}

Rururban Gentrification Territorial studies in La Florida (Manizales-Villamaria) and Cerritos (Pereira) Colombia

Gentrificação rururbana. Estudos territoriais em La Florida (Manizales-Villamaría) e Cerritos (Pereira), Colômbia

Beatriz Nates Cruz ${ }^{*}$

Paula Andrea Velásquez López ${ }^{*}$

Recibido: 15 de noviembre de 2017

Aprobado: 3 de octubre de 2018

Doi: http://dx.doi.org/10.12804/revistas.urosario.edu.co/territorios/a.6251

Para citar este artículo:

Nates Cruz, B., \& Velásquez López, P. A. (2019). Gentrificación rururbana. Estudios territoriales en la Florida (Manizales-Villamaría) y Cerritos (Pereira) Colombia. Territorios, (41), 143-170. Doi: http://dx.doi. org/10.12804/revistas.urosario.edu.co/territorios/a.6251

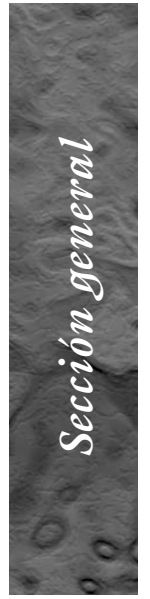

* Antropóloga, Universidad del Cauca, magister en Ciencias Politicas y Sociologia, Universidad Complutense de Madrid, doctora en Antropología Universidad Complutense de Madrid. Postdoctorado en Estudios Territoriales Comparados, Université de Paris III (Sorbonne-Paris -IHEAL-CREDAL). Docente de la Universidad de Caldas. Directora del Doctorado en Estudios Territoriales (ICSH, GIT, ANTROSOC). Correo electrónico: beatriz.nates@ucaldas.edu. co ORCID: http://orcid. org/0000-0002-3246-7903

* Trabajadora Social, Universidad de Caldas, magister en Territorio, Conflicto y Cultura, Universidad del Tolima, doctora en Estudios 
Palabras clave

Gentrificación rururbana,

residencialidad,

Manizales-Pereira, ordenamiento territorial.

Keywords

Rururban gentrification, residency, Manizales-

Pereira, territorial planning.

Palavras-chave

Gentrificação rururbana, residencial, ManizalesPereira, ordenamento territorial.

\section{territarias 41}

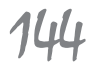

RESUMEN

Nuestro interés es la gentrificación rururbana en los bordes ${ }^{1}$ rural-urbanos. Lo que llamamos tercer territorio se materializa en un cuadro de vida urbano en lo rural, marcado por residencias, equipamientos y servicios urbanos que allí se establecen. Este fenómeno es una explosión en términos del hábitat, que va en detrimento ambiental y poblacional con serias implicaciones para el ordenamiento territorial rururbano. Metodológicamente recurrimos al método descriptivo a través de observaciones y entrevistas que brindan elementos para una etnografía territorial. En el análisis utilizamos la concepción local de las dinámicas territoriales y la normativa del ordenamiento territorial vigente. Los resultados presentan dos olas de población con cuadros de vida diferentes que se fueron asentando en estos lugares: neorurales entre las décadas de los 70 y los 80 con formas de vida tendientes a lo rural y urbanitas en el campo entre finales de los años $90 \mathrm{y}$ 2010 con formas de vida básicamente urbanas. Lo que constituye la gentrificación rururbana es el precio del suelo rural tazado como urbano, el impacto residencial y las infografías territoriales o marcas en el paisaje, que ocasionan una intempestiva transformación territorial sin que haya mediado una planificación de los gobiernos locales.

\section{ABSTRACT}

Our interest is the rururban gentrification on the rural-urban fringes ${ }^{2}$, which we call the third territory, that mainly embodies a city-like lifestyle in the countryside, marked by the residencies, urban services, and facilities that exist there. This phenomenon is a real explosion in terms of habitat, which is detrimental for the environment and the population, which has serious consequences for the rururban territorial-planning. Methodologically, we used the descriptive method based on observations and interviews that give us elements for a territorial ethnography. In the analysis, we used the local concept of territorial-dynamics and the territorial-planning regulations. The results present two population movements with different ways of life that settled in these places: neo-rurals between 70 s and 80 s with rural ways of life and urbanites in the countryside during the late 1990s and 2010 with essentially urban lifestyles. What marks the rururban gentrification is the price of rural soil rated as urban, the residential impact and territorial infographics or marks on the landscape that cause an untimely territorial transformation, without a mediated planning from local governments.

\section{RESUMO}

Nosso interesse é a gentrificação rurubana nas beiras ${ }^{3}$ rural-urbana. O que chamamos de terceiro território, materializa-se em um quadro de vida urbana no rural, marcado pelas residências, os equipamentos e serviços urbanos que ali se estabelecem. Este fenômeno, é uma explosão em termos do habitat, o que vai em detrimento ambiental e populacional com sérias implicações para o ordenamento territorial rurubana. Metodologicamente recorremos ao método descritivo através de observações e entrevistas que brindam elementos para uma etnografia territorial. $\mathrm{Na}$ análise utilizamos a concepção local das dinâmicas territoriais e a normativa do ordenamento territorial vigente. Os resultados apresentam duas ondas de população com quadros de vida diferentes que se foram assentando nestes lugares: Neo-rurais entre as décadas dos 70 e os 80 
com formas de vida tendentes ao rural, e Urbanitas no campo entre finais dos anos 90 e 2010 com formas basicamente urbanas. O que constitui a gentrificação rurubana é o preço do solo rural calculado como urbano, o impacto residencial e as infografias territoriais ou marcas na paisagem, que ocasionam uma intempestiva transformação territorial, sem que haja mediado uma planificação dos governos locais.

\section{Introducción}

La gentrificación ${ }^{4}$ es definida en principio por Glass (1964) y Smith (1996) como un fenómeno que se evidencia en los procesos de rehabilitación de los barrios de los centros de las ciudades considerados degradados. Se asume que el principal impacto son nuevas áreas económicamente más ricas y socioculturalmente más homogéneas y estandarizadas. Smith $(1996)^{5}$, considerado "el padre" de los estudios al respecto, plantea que es un fenómeno que comienza a vivirse en la postguerra y lo señala como una forma de reactivación socioespacial que comenzó a notarse hacia 1950 en barrios de Londres y Nueva York, y que en 1970 había afectado a las grandes ciudades de Europa.

La gentrificación se manifiesta en: 1) un cambio de composición social; 2) el mejoramiento o renovación de la arquitectura; 3 ) nuevas formas de desarrollo económico que se presentan como innovadoras y modernas con gran demanda en áreas de economía terciaria; 4) el alza en los precios de tierras y viviendas, y 5 ) el aumento desproporcionado de las remuneraciones o entradas y del nivel de educación en comparación con la población local.
En ese marco se han desarrollado estudios sobre la gentrificación rural donde se enfatiza que el factor residencial con gran oferta y demanda de vivienda es el mayor indicador de este fenómeno 2003; Nates-Cruz \& Raymond 2007; Guimond \& Simard 2010; Simard \& Guimond, 2012, 2013; Phillips \& Smith, 2018; Martí-Costa, Durán \& Marulanda 2016; Lorence Martiny, 2015; Janoschkaa, 2016; Janoschkaa \& Salinas Arreortua, 2017; Sabatini, Sarella \& Velásquez, 2008; Sabatini, 2015; entre otros). Nates-Cruz y Raymond (2007) señalan además que la gentrificación rural está ligada a una demanda creciente de "bienes rurales" o "bienes de naturaleza" que consumen los citadinos de sectores medios y superiores. Esto entra en lo que se conoce también como amenity migration.

La gentrificación rural y rururbana como problema territorial impacta en lo rural tanto o más que otros fenómenos ligados a la urbanización del campo. Sobre el estudio de la urbanización en el campo los impactos van desde la ruptura en la historia con una fuerte expansión de la sociedad urbana dominante (Gavignaud, 1990), la conformación de zonas rurales como cuadro de vida y no de lugares de (Phillips, 1993, 2000; Raymond 1994, de Caldas. Docente de la Escuela de Trabajo Social y Desarrollo Humano de la Universidad del Valle. Correo electrónico: paula. velasquez@correounivalle. edu.co ORCID: https://orcid.org/0000-0002-39678455

${ }^{1}$ La aclaración sobre los bordes está en que lo rururbano no solo es el territorio producido en las fronteras rural-urbanas, también está en lo rural ex-centrado (Ver Nates-Cruz, 2018).

2 The clarification on the fringes grounds on the fact that not only the rural-urban borders, but also the ex-centered rural produce the rururban territory (see Nates-Cruz, 2018).

${ }^{3} A$ aclaração sobre as beiras está em que o rururbano não só é o território produzido nas fronteiras rural-urbano, também está no rural ex-centrado (Ver Nates-Cruz, B. 2018).

${ }^{4}$ Aunque hay un intento por traducir el concepto como "elitización" (García, 2001), optamos por denominarlo con el anglicismo "gentrificación", por cuanto la bibliografía cientifica asi lo ha manejado. Además, este término da cuenta de lo que el proceso en sí significará en torno a $\Rightarrow$

tersitarios 41

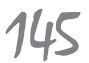


$\Leftarrow$

sus distintas categorias. Ver Neil Smith (1996).

${ }^{5}$ La obra se publica originalmente en inglés en 1996 bajo el titulo de: The New Urban Frontier: Gentrification and the Revanchist City, London and New York: Routledge.

${ }^{6}$ Para ampliar este debate consultar Nates-Cruz y Raymond, 2007.

${ }^{7}$ Condominio campestre o countries como lo llaman en Argentina.

\section{territarias 41} 146 producción (Hervieu 1979), hasta bifurcaciones económicas (Bradshaw, 1993) que no competen necesariamente a las disposiciones territoriales de lo $\mathrm{rural}^{6}$. Pero lo que sin duda marca los procesos de gentrificación, en particular rurales y en nuestro caso rururbanos, es el precio del suelo y el impacto residencial. La gentrificación está compuesta por una verdadera imbricación de actores sociales, económicos y ecológicos que repercuten en el ordenamiento territorial de un lugar, sin que los gobiernos tomen atenta nota de lo que está aconteciendo.

Partiendo de las tendencias que toman lugar desde hace casi cuatro décadas (Nates-Cruz \& Raymond, 2007; Richard, 2009 ) sobre casos de gentrificación en el campo, podemos decir que esta se define -según se conoce en la bibliografía al respecto: Andreani (1999), Boyle \& Halfacree (1998), Gerber (2000), Ghose (1997), Perrier-Cornet (2002)- como "el retorno a la naturaleza", que indica un modo de vida austero en armonía con ella y "el retorno a la tierra", como un modo de vida neocampesino con equilibrio medioambiental.

Por nuestra parte, precisamos la definición de la gentrificación rururbana como el establecimiento del "retorno al campo" objetivado en torno al modo de vida urbano que goza de las bondades del campo. Este retorno tiene varias expresiones en América Latina, en particular en México (Martínez, 2006; Ávila 2009; Lorence Martiny 2015; Janoschka 2016; Cardoso 2013, Hernández Flores et al.,
2014;), Brasil (de Queiróz Ribeiro, 2004; Milano, 2016) y Chile (Urzúa, 2013, Inzulza \& Galleguillos, 2014; Concha et al. 2014; Parra Carrasco, 2016;). En Argentina es vasta la bibliografía científica (Castelo 2007, Rojas 2007, Svampa 2008, Malizia 2011, Frediani et al., 2018, etc.) y hasta la literatura lo referencia, tal como lo muestra Piñeiro (2005):

En Altos de la Cascada ${ }^{7}$ las calles tienen nombres de pájaros. Golondrinas Batibú, Mirlo. No guardan un trazado lineal típico. Abundan los cul-de-sac, calles sin salida que terminan en una pequeña rotonda parquizada. Todos quisiéramos vivir en un cul-de sac. Pero en un barrio no cerrado, un callejón así, desvelaría el sueño de quien lo tuviera que transitar, sobre todo en la noche; temería ser asaltado, emboscado (p. 27).

En Colombia las referencias van desde tesis de pregrado y postgrado, hasta la literatura misma. Ejemplo de ello son los trabajos de Acosta (2009), Macuacé y Gómez (2014), Zuluaga (2005) y Traslaviña Rodríguez (2016).

Desde una perspectiva morfológica, la gentrificación rururbana se diferencia de la gentrificación rural en el desarrollo estratégico de equipamientos y conectividades viales. Lo que sucede en la vereda La Florida de Villamaría en ManizalesCaldas y en el corregimiento de Cerritos en Pereira-Risaralda, como lo veremos en registros posteriores, es una muestra contundente de ello. Surgen entonces las cuestiones que orientan este estudio: 
¿de qué manera y a través de qué se manifiesta la gentrificación rururbana? ¿Qué implicaciones socioculturales, económicas y políticas tiene este fenómeno con proyección a estudiar y gestionar lo rural contemporáneo? ¿Cómo incide este fenómeno en la ordenación del territorio?

\section{Metodología}

La metodología se basó en la etnografía territorial donde el territorio, más allá de ser un contenedor de los fenómenos sociales, es parte constitutiva de estos. Consideramos tres fases: descripción, inscripción y explicación de cuyos contenidos dan cuenta los materiales de paisajes, discursos y prácticas recogidas en un ensamblaje entre la geograficidad, la sociabilidad y la historicidad (contemporaneidad). En ese ensamblaje, los datos de tipo cuantitativo y cualitativo se trabajaron desde la lógica del modelo comprensivo que permite dar cuenta de las dimensiones, variables e indicadores que generaron los escenarios en cada una de las fases de la etnografía. En el trabajo de campo se consideraron las entrevistas dirigidas, los conversatorios domésticos, las observaciones directas (observar y preguntar) e indirectas (observar) y los muestrarios de fotografías y cartográficos. Se tuvieron en cuenta, para dar cierre a la etnografía territorial, los datos producidos a nivel fáctico por Planes de Ordenamiento Territorial (POT), Planes Básicos de Ordenamiento Territorial (РВOT) y Planes de Desarrollo
Municipal (PDM). También se consideró como herramienta complementaria para la depuración de categorías empíricas y analíticas software como Nvivo y HyperRESEARCH.

\section{Resultados y Discusión}

Como se ha mostrado en Nates-Cruz (2009, 2017), en Manizales y Pereira ese primer entusiasmo de citadinos por el campo comienza con los neorurales, un movimiento que tuvo lugar en los años 70 hasta avanzados los 80 . Se buscaba habitar los bordes donde la ciudad se veía a lo lejos como un lugar que se ubicaba en el centro. A esa ola le siguió otra que poco a poco fue "moviendo" la ciudad, ampliándola y haciendo de los barrios periféricos o de las veredas verdaderos lugares urbanizados. La búsqueda de los citadinos de un modo de vida en el campo no es entonces reciente.

\section{La Florida: el ocaso de un modo de vida hortícola}

A finales del siglo XIX la actual vereda La Florida era habitada por campesinos, cuya economía estaba basada en la horticultura. La trascendencia de tal actividad llevó a instaurar la Feria de la Horticultura en los años 60 del siglo Xx, fiesta que duró como exposición de la agricultura local hasta entrados los años 90 (Correa, 1999). Desde finales de dicha década y hasta la fecha, la feria no es más que una simulación de lo 
${ }^{8}$ En Colombia la división territorial que ubica condición social y económica se organiza por estratos. Estos van de 0 a 6 . El estrato 4 de La Florida corresponde a un tipo de poder adquisitivo y de ascenso social medio.

\section{territarias 41}

que fue antaño, puesto que el factor residencial de urbanitas es lo que predomina en el uso del suelo.

La vereda está ubicada entre los municipios de Villamaría y Manizales, cuya frontera la determina el río Chinchiná. Administrativamente pertenece a Villamaría. En los 90, la configuración espacial y social en esta vereda se transformó aceleradamente con la llegada de dos grupos. El primero estaba conformado por una población con poder adquisitivo medio-alto, que incluyó profesionales que laboraban en Manizales, algunos de ellos con una alta capacidad económica y otros, por el contrario, quienes se establecieron en la zona por medio de créditos hipotecarios. El otro grupo estaba conformado por habitantes de la vida pública con altos cargos laborales y capacidad adquisitiva. En esta década, según el Departamento Administrativo Nacional de Estadística (DANE, 2005), La Florida tenía 925 habitantes. En las proyecciones calculadas para el municipio de Villamaría, junto con los datos encontrados en el PBOT de 2000 , la vereda demuestra un crecimiento poblacional anual de $1.9 \%$ aproximadamente. A esto se suma el aumento en el número de viviendas, tema que en buena medida satisface la demanda del tipo de poblaciones mencionadas que en esa clasificación siguen arribando a La Florida hasta la fecha. Desde el año 2004 hasta 2015 , el número de viviendas se ha incrementado en 986 como se muestra en las tablas 1 y 2 .
Tabla 1. Crecimiento poblacional: Villamaría

\begin{tabular}{|c|c|c|c|c|}
\hline \multirow{2}{*}{ Año } & Urbana & Rural & \multicolumn{2}{c|}{ Población Total } \\
\cline { 2 - 5 } & \multicolumn{2}{|c|}{ No. de habitantes } & Incremento \\
\hline 2010 & 36582 & 9740 & 46322 & 3898 \\
\hline 2015 & 41084 & 9809 & 50893 & 5142 \\
\hline 2019 & 43984 & 10889 & 54873 & 4476 \\
\hline 2023 & 49188 & 9975 & 59163 & 4827 \\
\hline \multicolumn{5}{|c|}{ Total } \\
\hline
\end{tabular}

Fuente: Censo DANE 2005, proyección a 2023 estimada a 1.9\% tasa anual (Gómez \& Arias, 2012).

Tabla 2. Viviendas vereda Florida

\begin{tabular}{|c|c|}
\hline Año & Viviendas \\
\hline 2004 & 170 \\
\hline 2013 & 550 \\
\hline 2015 & 1156 \\
\hline
\end{tabular}

Fuente: La Patria (2013).

Consideramos que el desarrollo rururbano gentrificado que ha tenido esta vereda en comparación con otras de carácter rururbano de Manizales y Villamaría (Chupaderos, El Cerro de Oro o El Arenillo, etc.) radica en sus características paisajísticas; de condición de estrato ${ }^{8}$ para pago de impuesto predial bajo; de equipamientos, y de equidistancia con el centro urbano de Manizales y Villamaría. Además, esta vereda tiene elogiadas vistas hacia el volcán Nevado del Ruiz y un avistamiento de aves que se destaca en los condominios cerrados como unos de los privilegios de vivir en La Florida. Así lo 
presenta la constructora CFC\&A en cuanto a su conjunto cerrado Mocawa:

Ubicado en el sector de La Florida, justo al lado del conjunto Entreverde, en un entorno natural, acogedor y tranquilo; cerca al aeropuerto, a los mejores colegios de la ciudad, iglesias, supermercados y la clínica San Marcel. (...) Áreas comunes: Cuatro miradores, estancia para avistamiento de aves del bosque de Los Cantos (...), Sendero por el borde superior del bosque (Constructora CFC\&A, 2015) ${ }^{9}$.

Por otra parte, la condición predial de estrato 4 en la que está catalogada la vereda La Florida constituye un atractivo adicional tanto para los nuevos residentes, como para las empresas inmobiliarias que invierten en el uso del suelo. El impuesto predial es bajo si se tienen en cuenta los beneficios en extensión de los lotes de viviendas, sus construcciones y equipamientos. Los mismos predios en catalogación urbana se ubicarían en estratos 5 y 6 , aumentando ostensiblemente el costo del impuesto del predio. La rentabilidad sobre la vivienda como negocio puede en mucho deducirse de los permisos de construcción que mostramos a continuación (tabla 3 ).

Tabla 3. Permisos de construcción

\begin{tabular}{|c|c|c|c|c|c|}
\hline Vereda & 2012 & 2013 & 2014 & $\begin{array}{c}2015 \\
\text { (enero- } \\
\text { febrero) }\end{array}$ & $\begin{array}{c}\text { Total } \\
\text { permi- } \\
\text { sos }\end{array}$ \\
\hline La Florida & 26 & 28 & 31 & 6 & 91 \\
\hline
\end{tabular}

Fuente: Secretaría de Planeación de Villamaría (2015).
Este hábitat que se configura al mejor estilo de un patchwork, está en continua disputa no entre los campesinos de los cuales para 2015 ya no había más que dos familias, sino entre las inmobiliarias que se debaten a través de publicidades para lograr el mayor número de clientes (imagen 1).

Imagen 1. Modelos de planificación residencial por parte de inmobiliarias
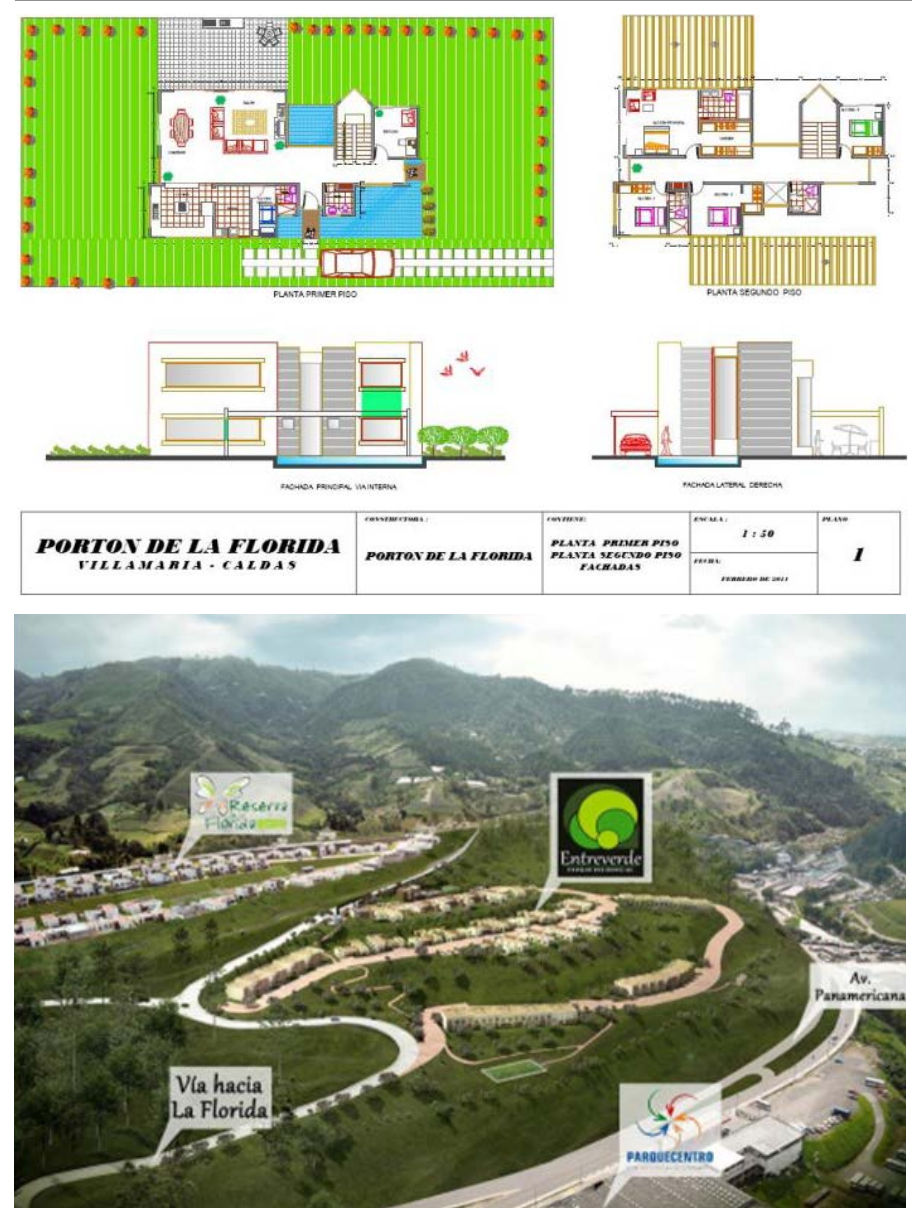

Fuente: https://www.bienesonline.co/ficha-casa-venta-manizales-caldas_CAV18526.php 
Los datos anteriores demuestran que la gentrificación rururbana alterna con una nueva forma de habitar conocida como condominios urbanos. Sin embargo, según se evidencia en la siguiente planimetría (mapa 1), continúan existiendo actividades agrícolas y pecuarias en ganadería a menor escala (de medianos terratenientes que, aunque no viven en la vereda tienen tierra de producción agropecuaria), pero nada de esto es tenido en cuenta de acuerdo con el aumento de permisos de construcción y la venta generalizada de tierras que terminará por urbanizarla por completo.

La influencia de Villamaría y Manizales sobre del crecimiento de la vereda

Mapa 1. Uso del suelo en La Florida

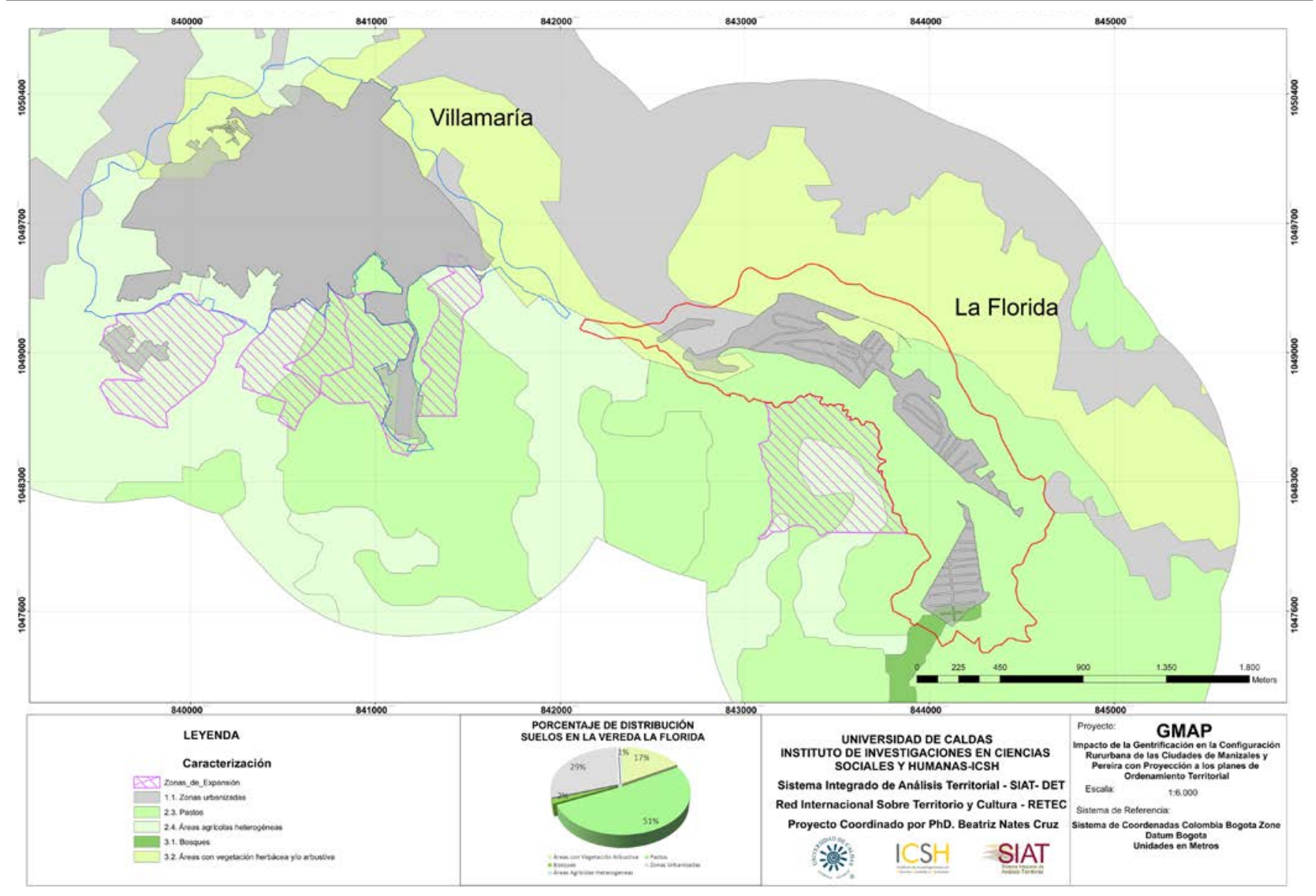

Fuente: Levantamiento con información del municipio de Villamaría (2012). 
La Florida no ha podido administrarse debidamente, lo que ha ocasionado una ruptura normativa a nivel del ordenamiento territorial. Esto permite inferir que las normas actuales del $\mathrm{PBOT}^{10}$ no son suficientes en la presente planificación, puesto que en poco contribuyen a lograr una armonización territorial de la futura área metropolitana que conecta los dos municipios, Villamaría y Manizales. Al contrario, se han incrementado todo tipo de problemáticas con la presión del uso del suelo residencial y de equipamientos, que deja poco espacio a otro tipo de uso, manejo y gestión de la vereda.

El desarrollo urbano en La Florida, liderado por las constructoras, no escatima en acomodarse a las ofertas con base en la valorización del uso del suelo. Esta situación ha ocasionado conflictos ambientales significativos que cuestionan los discursos de las inmobiliarias sobre la venta de una naturaleza ideal.

En el trabajo de campo se registró un conflicto ambiental que está en demanda por las acusaciones en doble vía de intervenir la quebrada La Florida, (hasta 1998): El Zanjón, que da frontera natural a una hacienda ganadera y a los propietarios de parcelas hortícolas del lecho de esta quebrada. El conflicto es entre un condominio que colinda a su vez con estas parcelas y la acusación por impacto de sus aguas en la quebrada que, consideran los dueños, afecta su producción agrícola. El asunto llegó a tal tensión que obligó a las partes a seguir la pista del problema biofísico y encontraron que todo provenía de la desviación del cauce de la quebrada que guiaba los meandros de la misma en sentido recto horizontal y no respetaba los cortes naturales del agua de la quebrada. Esta desviación - se consideró en la Asamblea de ese condominio - la había provocado de forma premeditada una constructora que tiene a su haber más de 300 viviendas al pie de la montaña de la vereda, en el perímetro de los únicos humedales que había en La Florida, los que por supuesto fueron secados para construir viviendas en el proceso de gentrificación rururbana.

Pero los conflictos ambientales pasan no solo por la mutua evasión de la responsabilidad sobre perjuicios a bienes ambientales naturales, sino también por otros asuntos como la deficiencia en el suministro de los servicios públicos de acueducto, agua potable, manejo de residuos sólidos y falta de alcantarillado. En un artículo del periódico La Patria se informa al respecto: "Alrededor del $60 \%$ de La Florida no tiene alcantarillado, por lo que utilizan pozos sépticos, mientras que el $40 \%$ restante tiene el servicio de manejo de aguas negras" (Salazar, 2012).

Bajo esta lógica de crecimiento, presión y cambio, La Florida se llena cada vez más de condominios y de actores citadinos, situación que deja ver tres elementos: 1) El desplazamiento simbólico o fáctico de la población nativa en número casi extinta; 2) El cambio de actividades tradicionales, y 3 ) La adaptación al cambio. De estos aspectos da cuenta una entrevista a uno de los gentrificadores e integrante de la Junta de Acción Comunal (2015),
${ }^{10}$ El vigente hasta la redacción de este articulo en 2015. tersitarios 41

151 
que habita la vereda desde el 2000, quien en un entramado de añoranza cruza las vivencias de los años 90 con la realidad que se mantuvo hasta inicios del año 2000:

Varios son los componentes del desplazamiento tanto material como simbólico de los campesinos nativos de la zona [que en número ya no restan sino dos familias de un total aproximado de 20 personas]. El primero tiene que ver con la llegada acelerada de citadinos a la zona, hecho que ha generado que se empiece a lotear las fincas que antes eran dedicadas a lo hortícola y a la ganadería [fincas que se lotean de manera agresiva desde el año 2000 hasta el presente]. El segundo componente es que dicho desplazamiento lo que ha ocasionado es la disminución de actividades tradicionales como la venta de leche y la venta de productos hortícolas [que se mantuvo hasta el año 2010]. Antes [entre los 90 y 2010] por ejemplo, uno o dos campesinos surtían de leche a toda la vereda. Eso, con la llegada de otros actores, disminuyó notablemente pues uno de los campesinos que para ese entonces tenía de 10 a 15 vacas, aproximadamente, ahora [las dos familias actuales] ya solo tiene dos o tres, y surte a pocos vecinos de leche [ya nadie está interesado en comprar ese tipo de leche] (Entrevista, habitante de la Florida, trabajo de campo, abril 2015).

Según los entrevistados, varias familias de campesinos de la Florida se "bajaron" a vivir al barrio Los Molinos en alquiler o en casas propias en condiciones inadecuadas.

\section{tersitarias 41} 152 ubicación de los condominios que por su morfología producen mayores presiones del suelo sobre la cuenca y las microcuencas del río Chinchiná. Las construcciones están fabricando verdaderas descargas de cemento que cada vez deja menos respiro al prometido encanto rural de esta. Buen ejemplo de lo dicho son los conjuntos residenciales Mocawa, Terranova, La Florida y Entreverde referenciados en el mapa 2.

A lo anterior se agrega la extensión de la malla vial deficiente (los automotores no pueden pasar de manera adecuada) y el aumento desproporcionado de vehículos. En 800 casas aproximadas que pudimos constatar en agosto de 2015 , cada una contaba con al menos un automóvil. Complica aún más la presión ambiental y la sobre carga del suelo, el aumento de colegios privados. Para los nativos el único colegio que debería existir de forma legítima - por no ocasionar este tipo inconvenientesporque ha estado allí desde la fundación de la vereda es la institución pública educativa Nuestra Señora del Rosario. Esta presión se objetiva en el aumento de circulación de vehículos, de servicios ecoambientales y servicios públicos para el funcionamiento de colegios e iglesias.

El turismo religioso que viene en aumento desde hace 20 años ha generado un volumen importante de tránsito automotor y caminantes a comienzos y finales de cada mes, en la romería al Santuario de la Virgen de los Pobres y de las Naciones. A ello se suma la nueva forma de uso de la iglesia de antaño de La Florida, San Juan María Vianey, que desde hace diez años es 
Mapa 2. Ocupación en La Florida

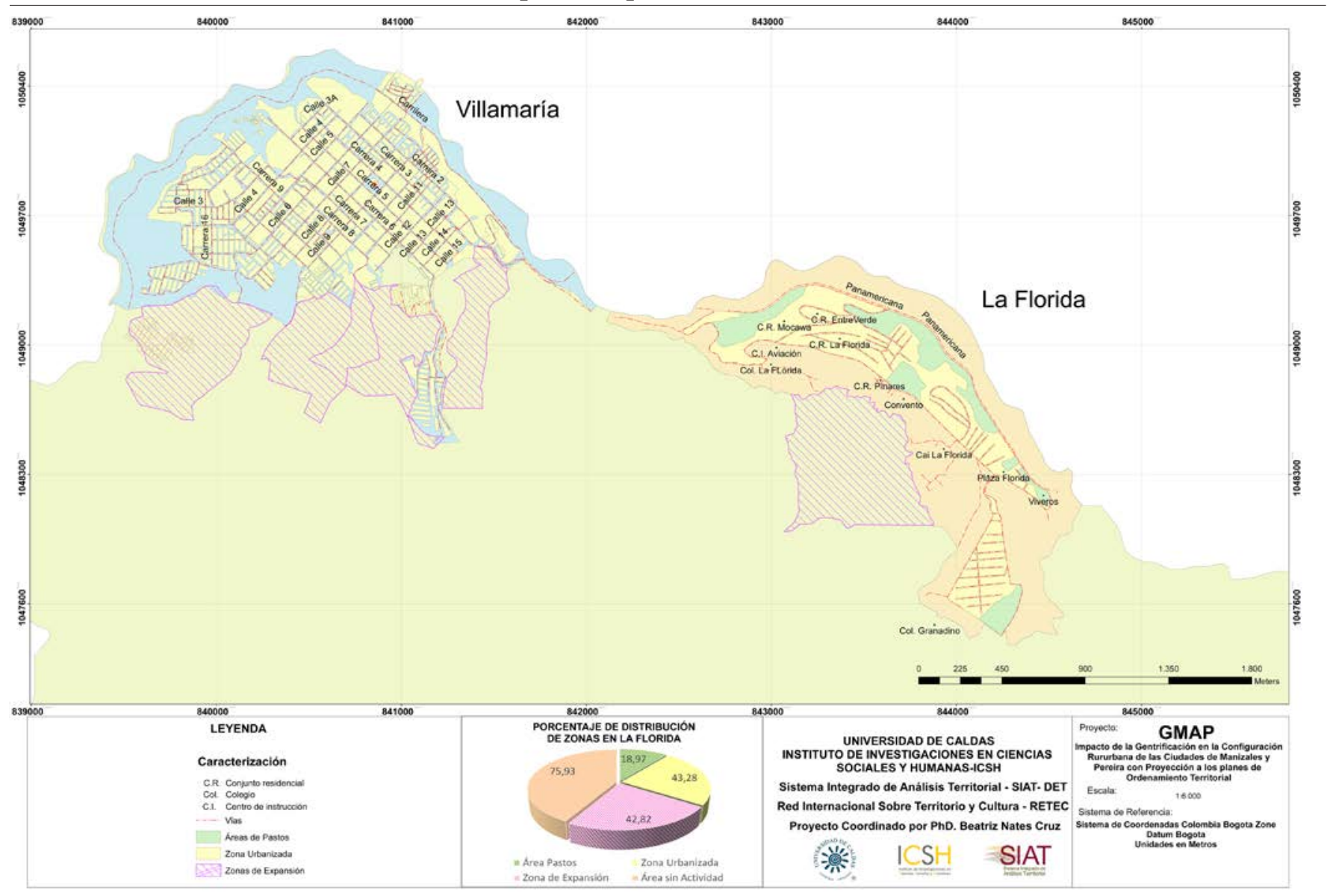

Fuente: levantamiento propio con información del municipio de Villamaría (2102).

cada vez más solicitada para la celebración de matrimonios y primeras comuniones por las élites de Manizales, que la han tomado como su ermita.

Los fenómenos descritos generan dos elementos más a tener en cuenta. El primero tiene que ver con adaptar el impuesto municipal de plusvalía, puesto que este no indica la valoración real del suelo, pero sí refleja el costo de una vivienda construida como claro indicador de aumento económico. Esta situación se pone en evidencia en una transacción de compra-venta de vivienda: un lote de $630 \mathrm{~m}^{2}$ de extensión y $250 \mathrm{~m}^{2}$ construidos puede tener impuestos anuales de 2 millones de pesos por ser territarias 41 
estrato 4, su costo como vendida puede llegar a 800 millones de pesos. Esto no corresponde con el impuesto pagado, de allí que no haya relación entre estrato, impuesto predial y costo de venta. El segundo elemento surge de la combinación de la forma, localización, plusvalía y dinámicas socioculturales que introducen cambios sustanciales en la decisión del Concejo Municipal de Villamaría para definir que la vereda pasará para efectos prediales a ser considerada un barrio de Villamaría en estrato 4. Esto es lo que expresa como una proyección de la política el Acuerdo 070 de 2007 para PBOT, Artículo 52 y Artículo 157. En dicha proyección así se ha manejado desde hace aproximadamente

Imagen 2. En la Florida (Villamaría) dicen que crecen en medio de dificultades

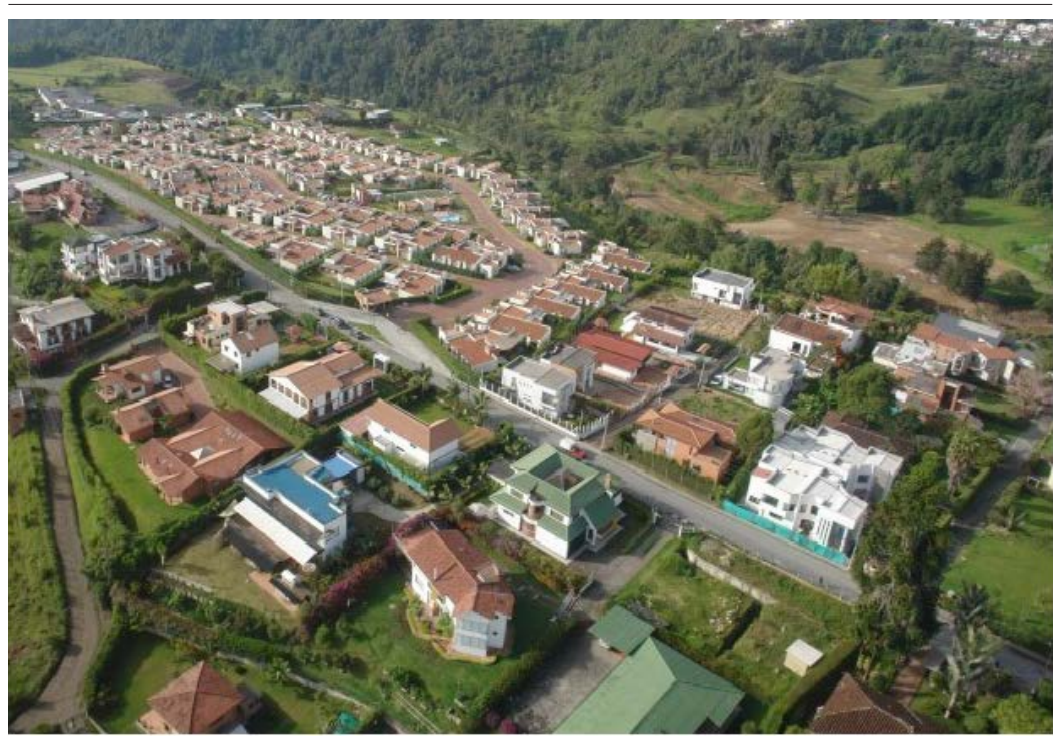

Fuente: La Patria (2013).

154 un año y medio tomando como base el tiempo de estudio del presente texto.

Estos problemas de gentrificación rururbana son evidenciados particularmente en el periódico local La Patria. Allí, siete artículos fueron publicados en un periodo aproximado de cinco años con temas variados respecto al fenómeno. Los más reiterativos discuten el paso de la vereda a barrio, el ambiente campestre de la vereda como motivación del crecimiento poblacional, el alto costo de los predios y problemas en el alcantarillado y alumbrado público (imagen 2 ).

Los cambios en los últimos años en estos escenarios, sus nuevos actores políticos, sus relaciones complejas de vecindad y las relaciones de poder que se adelantan e invisibilizan al campesino dejan entrever un ejercicio vertical de la forma en la que se están gestionando estos territorios. Desde esta óptica se ven claramente las fuertes alianzas de filiación para abrir espacios institucionales que permitan la participación de actores citadinos en el debate político,

postulando a un miembro que forma parte de los llegados de la ciudad para que pueda formar parte del Concejo de Villamaría y de esta forma poder llegar más allá de una organización meramente local que no impactó más ampliamente (Entrevista a habitante de la Florida, trabajo de campo, abril 2015).

El entrevistado forma parte de la Junta de Acción Comunal de la vereda hoy ocupada por los citadinos de La Florida, quien hace referencia al movimiento generado 
para postular a uno de sus miembros al Concejo de Villamaría, asumiendo que las 800 casas que existen hoy serán una fuente de votos seguros para lograrlo y que con ello traerán logros como la merma de impuestos y la implementación de mejores equipamientos.

Veamos a continuación las apuestas, sus complejidades y contradicciones. En el 2000, el municipio de Villamaría formuló el PBOT mediante el Acuerdo 044, y aún a la fecha de redacción de este texto (febrero de 2015), no se había presentado ni aprobado el nuevo, regido por la Ley Orgánica de Ordenamiento Territorial (LOOT) de 2011. En este PBOT se vincula La Florida como vereda. En el año 2007 se realizó una revisión del documento y se tuvieron en cuenta algunas dinámicas de cambio en el uso del suelo de la vereda y esta, según el Acuerdo 070 del 9 de marzo de 2007, pasó a tener suelos urbanos y de expansión urbana. En el último plan de desarrollo del municipio llamado "Villamaría hacia la sostenibilidad con calidad social, económica y ambiental" que se ejecuta de 2012 a 2015, la vereda está clasificada como zona hortícola media.

En dichas clasificaciones y desde el PBOT y el Acuerdo 070 en particular, la zona oriental de La Florida, que es la zona de expansión, debe tener los siguientes sistemas estructurantes:

Durante la vigencia del Plan Básico de Ordenamiento Territorial del Municipio de Villamaría, el suelo de expansión que se ha dotado de servicios públicos domicilia- rios, alcantarillado y energía, así como de vías principales y secundarias de acceso, se incorporará a la categoría de suelo urbano, siempre y cuando cuente con la totalidad de estas dotaciones. En todo caso para su inclusión deberán pagar la plusvalía conforme a lo establecido en la Ley 388 (Alcaldía Municipal de Villamaría, 2007, p. 43).

Para el desarrollo de estas zonas, es necesario realizar planes parciales que, además de garantizar una adecuada planeación, tengan en cuenta que los suelos que serán incorporados al suelo rural están obligados a pagar plusvalía. Igualmente, se debe tener en cuenta que el área mínima de los predios para los proyectos de vivienda es de $540 \mathrm{~m}^{2}$, pues el mismo PBOT estipula que estas áreas deben estar debidamente dotadas de servicios públicos domiciliarios, acueducto, alcantarillado, energía y vías.

En el Acuerdo 070, específicamente en el capítulo 15, La Florida entra a formar parte de las áreas morfológicas homogéneas en el suelo rural con las siguientes características: igualdad en cuanto a usos, morfología, integración espacial y/o funcional. Esta definición tiene en cuenta el soporte físico natural, la morfología que ha adquirido la vereda, la malla vial, los equipamientos, la división política administrativa, los condominios, las parcelaciones y la reformulación en cuanto al área construida, la cual es de $3000 \mathrm{~m}^{2}$. En el análisis de este conjunto de variables físicas y socioeconómicas es posible ver, en comparación con el PBOT del 2000, que el área mínima aprobada 
de construcción disminuyó $1000 \mathrm{~m}^{2}$, de los $4000 \mathrm{~m}^{2}$, que se exigían antes, lo que sin duda generará más demanda y presión habitacional de citadinos.

Ahora bien, las distintas vinculaciones de la vereda al ejercicio de ordenamiento y planificación han evidenciado que no existe una articulación de procesos en términos de normatividad ni en los instrumentos para gestionar el ordenamiento territorial. A esto se une otro aspecto que tampoco es abordado en el PBOT ni en el PDM ni en el Acuerdo 070. Nos referimos al ya firmado acuerdo entre alcaldes para conformar el área metropolitana (Alcaldía de Manizales, 2013). Esta red de relaciones que giran en torno a la cercanía, lo económico, la movilidad y al trabajo, entre otras cosas, olvida que quizá la expansión no es de Villamaría hacia Manizales, sino de esta hacia las inmediaciones de La Florida. La primera gana en impuestos y plusvalía; la segunda, en "deshacerse" de una presión habitacional para un tipo de población que exige condiciones de instalación que Manizales no está en condiciones de ofrecer por razones que van desde su topografía, hasta sus recursos.

En resumen, en estas dinámicas territoriales se han generado en La Florida, con la enajenación de las administraciones de Villamaría y Manizales, cuatro factores que aún no se tienen en cuenta en las políticas territoriales de estos municipios: 1) La gentrificación genera cambios desbordados en el uso del suelo en términos de vivienda, vías de comunicación, zonas de confort (senderos, canchas de deportes, piscinas, etc.), centros de alimentos, agua potable, tratamiento de residuos sólidos; 2) La debilidad de la visión regional que apenas queda insinuada en los PBOT y PDM frente a la conectividad del sistema orográfico y el impacto que tiene la gentrificación rururbana en la cuenca del río Chinchiná, eje que articula y conecta a La Florida con los municipios aledaños; 3) El ejercicio prospectivo de los territorios cuyas dinámicas aluden a reconfiguraciones territoriales que crecen a la luz de lo político, lo social, lo económico y lo cultural presentes en los intersticios rurales-urbanos, y 4) La necesidad de mecanismos de seguimiento y monitoreo cartográfico que permitan visualizar actualidades, retrospectivas y perspectivas en el "ensanchamiento" de La Florida y su impacto estructural en la configuración contemporánea entre Villamaría y Manizales.

\section{Cerritos: la explosión de la renta urbana}

El corregimiento de Cerritos se localiza en el centro occidental del municipio de Pereira, a una distancia de $15 \mathrm{~km}$ de la ciudad (ver mapa 4). Posee un área aproximada de 4386 ha. Cuenta con una población que ronda los 8579 habitantes y según el DANE (2005) el 74.99\% de la población pertenece a los estratos 1 y 2 . Este corregimiento posee 7 veredas, una de las más pobladas recibe el mismo nombre: Cerritos con 1607 habitantes, la otra, Galicia Alta, tiene 2601.

\section{territarias 41} 156 
Hasta iniciada la década de 1990 primaba en Cerritos la ganadería, seguida de los cultivos de piña con 50.98 ha equivalentes al $7.29 \%$, lo que lo posicionó como el segundo sistema productivo de explotación de interés económico en el departamento. De este y más cultivos da cuenta la tabla 4.

Tabla 4. Usos del suelo en el corregimiento Cerritos

\begin{tabular}{|l|c|c|}
\hline \multicolumn{1}{|c|}{ Uso } & Area (Ha) & $\%$ \\
\hline Cítricos & 8.52 & 1.22 \\
\hline Guanábana & 1.55 & 0.22 \\
\hline Piña & 50.98 & 7.29 \\
\hline Yuca & 5.58 & 0.80 \\
\hline Vivienda campesina & 5.58 & 0.80 \\
\hline
\end{tabular}

Fuente: Plan de manejo ambiental para la conservacion del bosque seco tropical "palo alto" al occidente de Cerritos. Pereira. (Hincapié \& Valencia, 2011).

El crecimiento demográfico proyectado por la Secretaria de Planeación para el año 2012 en el corregimiento de Cerritos no se aleja de los proyectados a nivel municipal, puesto que de 2008 a 2013 se tuvo un incremento considerable como se puede observar en la tabla 5.

El corregimiento está clasificado dentro de las categorías de suelo de expansión y suburbano. Para el proceso de la gentrificación rururbana en los suelos de expansión desde la década de los noventa, se evidencia un crecimiento acelerado de la población de poder adquisitivo medio
Tabla 5. Aproximación de población estimada para el corregimiento de Cerritos 2005-2015

\begin{tabular}{|l|c|c|c|c|c|}
\hline \multicolumn{1}{|c|}{ Area } & $\begin{array}{c}\text { Viviendas } \\
\text { Censo }\end{array}$ & Hogares & $\begin{array}{c}\text { Personas } \\
\mathbf{2 0 0 5}\end{array}$ & $\begin{array}{c}\text { Proyección } \\
\text { población 2010 }\end{array}$ & $\begin{array}{c}\text { Proyección } \\
\text { población 2015 }\end{array}$ \\
\hline Cabecera & 99713 & 100946 & 358681 & 383623 & 408563 \\
\hline Rural & 18061 & 17583 & 69716 & 73480 & 77244 \\
\hline Total & 117774 & 118529 & 428397 & 457103 & 485807 \\
\hline
\end{tabular}

Fuente: a partir de los datos del DANE, censo de 2005.

alto y alto y la multiplicación atomizada de condominios y chalets, junto con la renovación de fincas que antes eran dedicadas al cultivo de café, muchas de las cuales son desde hace 10 años hoteles rurales. Estas características subrayan la multiplicación de equipamientos y servicios tales como supermercados, estaciones de gasolina, restaurantes y centros recreacionales, los cuales a su vez tienen alta demanda de servicios domiciliarios.

En cuanto a los suelos suburbanos, encontramos que tienen una participación en hectáreas de 2879 , las cuales están atravesadas por la vía que comunica a Pereira-Cerritos-Cartago. La cantidad de hectáreas se especifican en la tabla 6, que junto con el mapa 3 de uso de suelo (mapa 3) ofrecen un panorama del lugar.

Tabla 6. Hectáreas de suelo suburbano en el corregimiento de Cerritos

\begin{tabular}{|c|c|c|c|}
\hline Lugar & $\begin{array}{c}\text { Total } \\
\text { hectáreas }\end{array}$ & $\begin{array}{c}\text { Hectáreas suelo } \\
\text { suburbano }\end{array}$ & $\%$ \\
\hline Cerritos & 4041 & 2879 & 37.06 \\
\hline
\end{tabular}

Fuente: Elaboración propia a partir del Plan de Desarrollo de Cerritos 2007-2016 y el POT de Pereira 2000. territarias 41

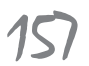


Mapa 3. Uso del suelo en Cerritos (Pereira)

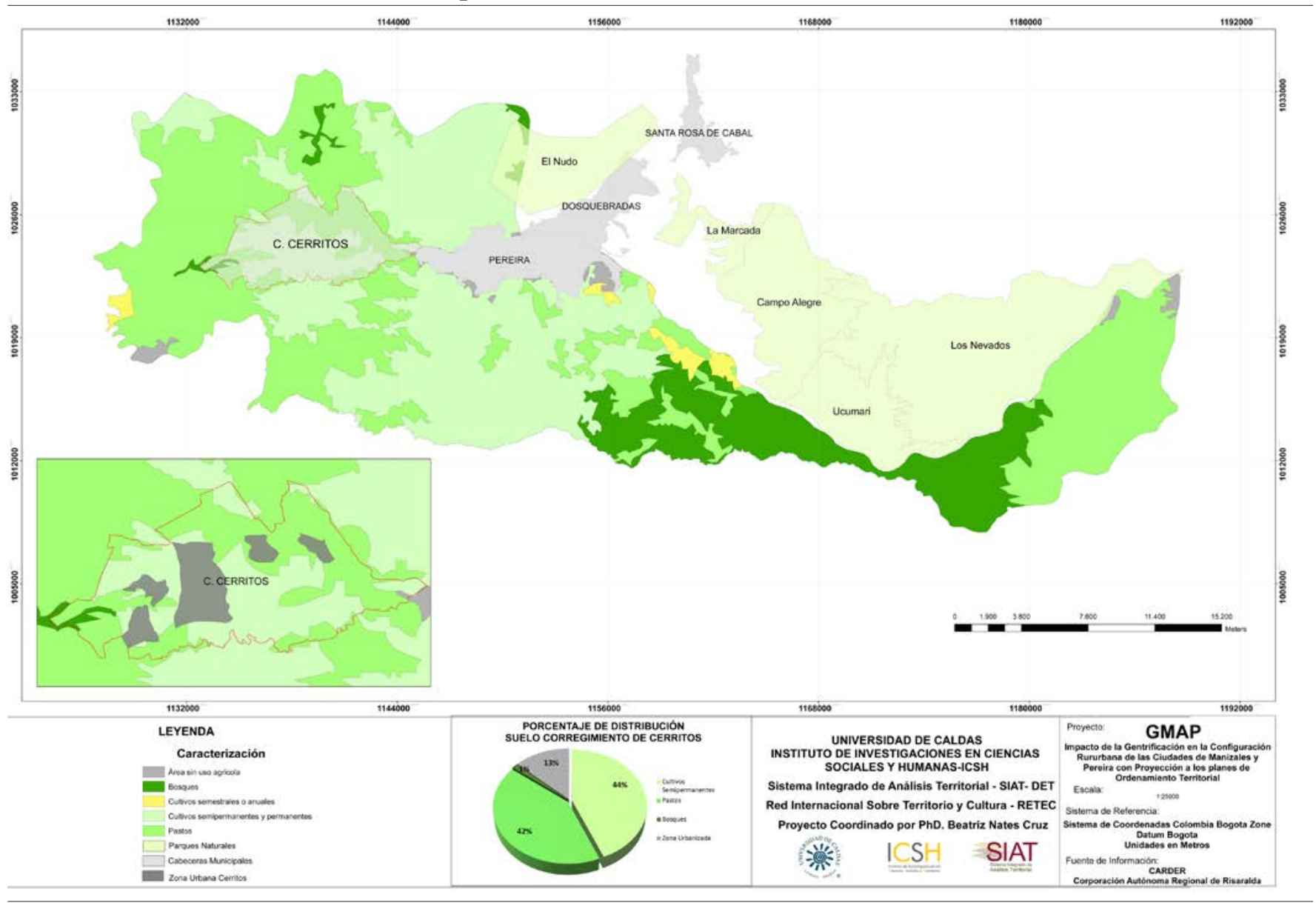

Fuente: levantamiento propio con información de la Carder (1994).

En Cerritos, el uso residencial es la actividad de mayor intensidad y desarrollo y se conjuga con asentamientos campesinos, parcelaciones de viviendas campestres y condominios. Una de las consecuencias de dichos fenómenos es "el crecimiento de los asentamientos sobre los corredores

tersitarias 41 158 viales, además de irse desarrollando con un nivel de dispersión bastante notorio, se han desarrollado sin ningún tipo de control predial y control espacial" (Marulanda, 2014 , p. 62).

Es importante señalar que la dinámica de la renta y venta en la frontera ruralurbana empieza a tomar fuerza en el corregimiento y en algunas de las veredas 
más grandes porque las inmobiliarias están rentando o vendiendo condominios como opción de vivienda para algunas personas que prefieren vivir en la periferia en condiciones óptimas de campo-ciudad. Según datos de la Secretaría de Gestión Inmobiliaria, el canon promedio de arrendamiento para 2015 era de \$1 071500 mensuales.

Según Osorio y Silva (2007) en el primer trimestre de 2007 se reportaron 260 negocios en el área rururbana y rural del municipio de Pereira. En Cerritos, las transacciones de compra-venta fueron de 44 en total, con una participación o de la ganancia del negocio de un $16.92 \%$. En las operaciones registradas en el municipio, el corregimiento de Cerritos cuenta con la mayor participación, seguido de Morelia y Combia Alta, lo cual refleja una tendencia hacia proyectos de condominios campestres y parcelaciones en estos corregimientos (Osorio \& Silva, 2007). Así, en términos de planificación, estos espacios rurales emergen como usos de carácter urbano que poco a poco se van consolidando a partir de los nuevos usos del suelo con mayor demanda.

Otro de los elementos estructurantes del suelo suburbano que se refleja en la normatividad del municipio de Pereira es la vivienda, para la cual se permite una densidad de 4 por hectárea bruta, en modalidad de condominio o parcelación, que pueden ocupar el 30\% del área neta del predio; para otros usos se permite en el caso del comercio, en servicios e industria la ocupación del 50\% del área neta, y para equipamientos colectivos, el $40 \%$ del área neta. El índice de construcción permitido está en un 30\% para cualquier uso y el área mínima de lote es de $1500 \mathrm{~m}^{2}$ para condominios y de $2000 \mathrm{~m}^{2}$ para otros usos. Entre 2006 y 2011 fueron aprobadas 263 licencias para construcción de vivienda unifamiliar en el suelo rururbano, mientras que de comercio, industria y servicios se aprobaron 22 (Giraldo, 2013, p. 78).

Los datos mencionados anteriormente muestran la fuerte dinámica residencial que se genera en el suelo rururbano, tema que simultáneamente propicia, a nuestro criterio, un tipo de transformación que se presenta no solamente por las relaciones funcionales de Pereira como ciudad y como parte del área metropolitana, sino también por las relaciones locales al interior del municipio. Frente a este tema, en particular Giraldo (2013) ofrece una mirada detallada en el estudio: Planificación Ambiental Territorial, de lo que él llama suelo suburbano del municipio de Pereira:

Existe al interior del Municipio una relación directa de movilidad entre los habitantes de estas dos clases de suelo, representada por un flujo constante de habitantes que residen en el suelo suburbano y que tiene su lugar de trabajo o estudio en el área urbana del Municipio (...) Dada la inmediatez del suelo de expansión con el suelo suburbano, es fundamental destacar que, con la dinámica de urbanización propia de la implementación de planes parciales en el territorio, es cada vez mayor la relación urbana con la suburbana. (...) la relación entre el suelo suburbano y el rural se fundamenta territarias 41

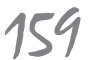


especialmente en la localización inmediata que hay de estos en el territorio y la función que ejerce el suelo suburbano como área de transición de lo urbano a lo rural; espacio de transición que en la actualidad se caracteriza por sufrir proceso de subdivisión, o parcelación que en muchos casos cambia su uso productivo, o uso del campo, a un uso urbano en especial para la conformación de viviendas campestres o segundas viviendas propias de los habitantes del suelo urbano perdiendo así su vocación rural (p. 73).

Las relaciones mencionadas dan cuenta de un territorio en continuo intercontacto y movimiento que juega un papel económico relevante de actores sociales y políticos como relación dentro de las tendencias emergentes de gentrificación rururbana. Es así como en términos de planificación y ordenamiento en el corregimiento de Cerritos se puede ir comprendiendo cómo en los espacios rurales emergen usos de carácter urbano que paulatinamente se van consolidando como los nuevos usos del suelo de mayor demanda.

En términos del POT como el eje de mayor impacto de la gentrificación rururbana, podemos decir que el suelo de expansión urbana está:

Constituido por la porción del territorio municipal destinada a la expansión urbana, que se habilitará para el uso urbano durante la vigencia del plan de ordenamiento, según lo determinen los Programas de Ejecución.

\section{tersitarias 41}

y a la posibilidad de dotación con infraestructura para el sistema vial, de transporte, de servicios públicos domiciliarios, áreas libres, y parques y equipamiento colectivo de interés público o social. Dentro de la categoría de suelo de expansión podrán incluirse áreas de desarrollo concertado, a través de procesos que definan la conveniencia y las condiciones para su desarrollo mediante su adecuación y habilitación urbanística a cargo de sus propietarios, pero cuyo desarrollo estará condicionado a la adecuación previa de las áreas programadas (РОT Pereira, Risaralda 2000).

El suelo rururbano que en la literatura oficial de Pereira y de algunos autores al respecto se denomina suelo suburbano, se define como:

Las áreas ubicadas dentro del suelo rural, en las que se mezclan los usos del suelo y las formas de vida del campo y la ciudad, diferentes a las clasificadas como áreas de expansión urbana, que pueden ser objeto de desarrollo con restricciones de uso, de intensidad y de densidad, garantizando el autoabastecimiento en servicios públicos domiciliarios, de conformidad con lo establecido en la Ley 99 de 1993 y en la Ley 142 de 1994. Podrán formar parte de esta categoría los suelos correspondientes a los corredores urbanos interregionales. Los municipios y distritos deberán establecer las regulaciones complementarias tendientes a impedir el desarrollo de actividades y usos urbanos en estas áreas, sin que previamente se surta el proceso de incorpo- 
ración al suelo urbano, para lo cual deberán contar con la infraestructura de espacio público, de infraestructura vial y redes de energía, acueducto y alcantarillado requeridas para este tipo de suelo (POT Pereira, Risaralda 2000).
En el mapa 4 se puede observar la ocupación de los usos referentes al suelo suburbano y de expansión del suelo en el corregimiento de Cerritos. Dentro de estas clasificaciones que realiza el POT hay un punto álgido: se desconocen las dinámicas contemporáneas que tienen que ver con que en 2015 encontráramos en el

Mapa 4. Ocupación corregimiento de Cerritos en el municipio de Pereira

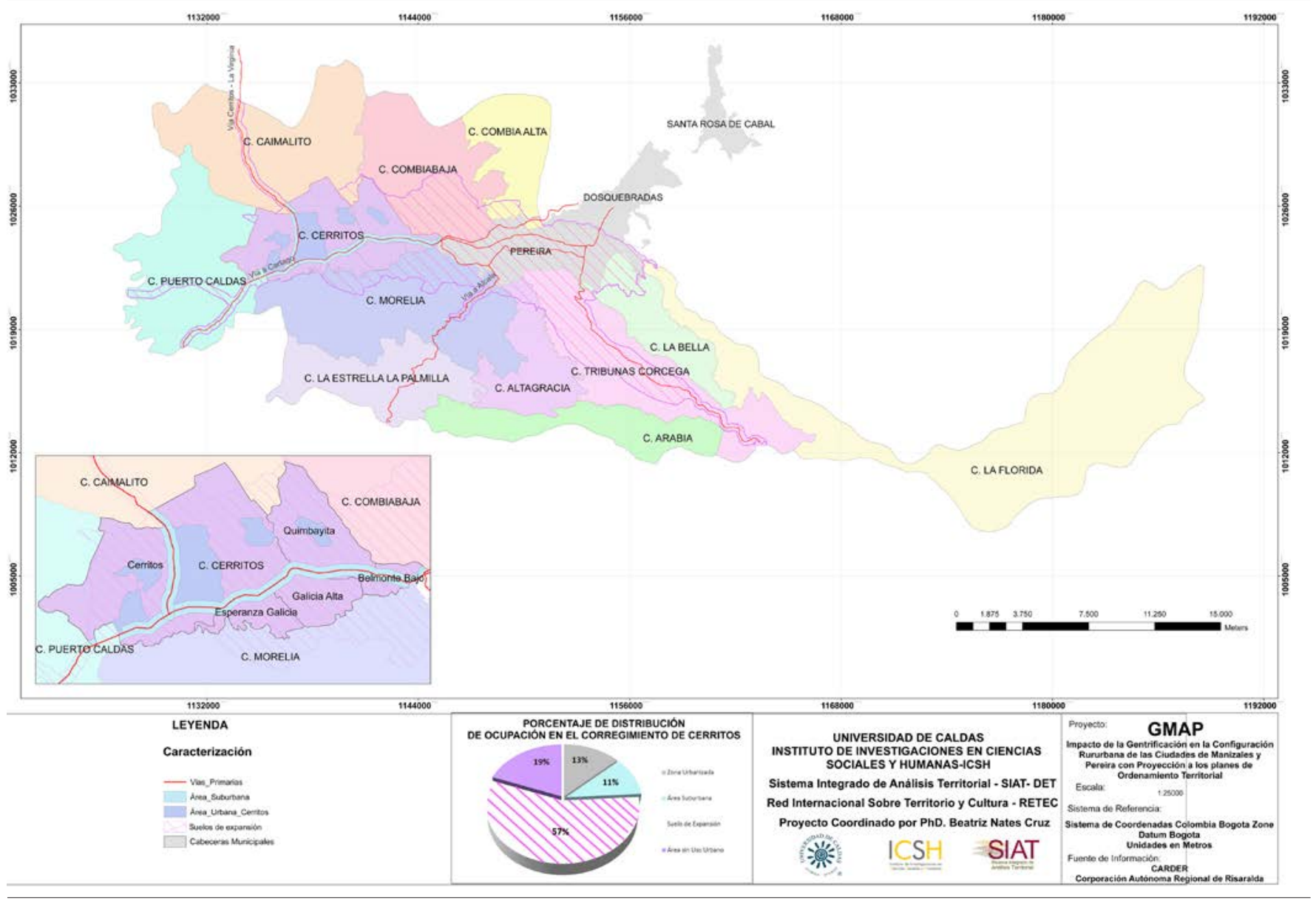

Fuente: levantamiento propio con información de la Carder (1994). 
corregimiento condominios, finca-hoteles, casas campestres, zonas residenciales y comerciales, entre otros, que se conjugan con gentrificadores urbanistas de poderes adquisitivos por encima de la media nativa del corregimiento. Este contexto por demanda, oferta u omisión de servicios genera tensiones de distinta índole. Por otra parte, los datos del POT no arrojan límites claros ni precisos frente a cuánta tierra del corregimiento corresponde a una u otra clasificación ni la ocupación de los suelos entre actores sociales citadinos y nativos.

Es necesario tener en cuenta también que para el caso de Cerritos en Pereira la categoría de suburbanización, además de ser una subcategoría de lo rural, es un proceso reglamentado desde el POT; es decir, que no se trata de un proceso espontáneo, sino de un proceso que está reglamentado institucionalmente. Ejemplo de ello es que en el POT del 2000 las áreas de construcción permitidas para Cerritos eran de $1000 \mathrm{~m}^{2}$ en condominios y $1500 \mathrm{~m}^{2}$ en lotes independientes, normativa que cambió con el Acuerdo 023 de 2006, por medio del cual se adoptó el ajuste y revisión que se realizó al POT, ya que permitió predios en condominios desde $1500 \mathrm{~m}^{2}$ y lotes independientes para vivienda desde $2000 \mathrm{~m}^{2}$. Esto muestra, como en el caso de La Florida, una manipulación de extensiones vs. áreas de construcción, que sin duda está mediada por la oferta y la demanda en ganancia con plusvalía e impuesto predial.
Paralelamente a las áreas construidas, el POT permite en los suelos suburbanos el uso de tipo residencial, equipamiento y agropecuario, y para los corredores viales toda clase de usos desde residencial, comercial, hasta servicios, equipamiento e industria. Sin embargo, "la dinámica del mercado inmobiliario tiende a la consolidación de usos residenciales principalmente, desplazando las actividades agropecuarias y agroindustriales" (Giraldo 2013, p. 145).

El POT genera unos parámetros para la delimitación tanto de los suelos de expansión como de los suelos suburbanos. En dichos criterios se asumen los siguientes aspectos: para el suelo de expansión urbana se consideran las proyecciones de crecimiento de la ciudad, la oferta de áreas vacantes dentro del perímetro urbano y sanitario; las demandas del suelo que requiere la población actual para suplir el déficit de vivienda; los consumos del suelo que requiere la población futura; los indicadores de consumo de suelo histórico; los estándares mínimos de calidad de vida, y la cobertura de alcantarillado y acueducto. Para el suelo suburbano, se consideran como criterios corredores suburbanos con tendencia a la conurbación urbana, corredores suburbanos con tendencia a la articulación regional, nodos interregionales, centros suburbanos y usos del suelo.

Ahora bien, existen varias debilidades en la consecución administrativa de dichos criterios pues no se específica en el POT tersitarias 41 
una normatividad clara para los diferentes usos de vivienda. Tampoco se especifica en dichos criterios las particularidades locales en términos de la creciente reconfiguración territorial a nivel sociocultural, político, organizativo y económico, enmarcando los criterios de ordenamiento y clasificación del territorio en criterios que más que todo resaltan los componentes viales y ambientales. Además, no se atienden los procesos de cambio en uso del suelo armonizados con las nuevas funciones socioculturales, tema que en buena medida complementa la planificación económica y social con la territorial.

Así, el fenómeno de gentrificación rururbana da cuenta de zonas rurales con usos urbanos diferentes según el contexto sociocultural desde poblaciones campesinas y citadinos, hasta zonas de comercio y servicios. Igualmente evidencia la nueva demanda de empleo terciario, dinámica que prolifera en espacios intersticiales y que no es tenida en cuenta ni en la planimetría ni en el ordenamiento territorial. En cuanto a la información cartográfica que propicia de manera sustancial los datos adecuados del ordenamiento territorial, se encontró que toda la planimetría que se obtiene en planeación, en términos de estructura, proporciona buena información en cuanto a vías, uso del suelo y equipamientos, entre otros. Sin embargo, pudimos constatar que los instrumentos cartográficos presentan problemas en términos de superposición y de ajustes en las curvas de nivel.

\section{Conclusiones}

Pensar en un tercer territorio ${ }^{11}$, que es lo que surge en esa plataforma rururbana, debe servir para pensar el concepto pero también la política y sobre todo la inclusión de todos los actores en este. En ese derecho tripartito a la geografía, la sociedad y la historia, hay una conjunción que en el caso de la gentrificación, y en particular en la rururbana, pasa por el concepto de "residencia" y "vivienda", que presentan un doble juego: con ella se territorializa y se sientan las bases de la gentrificación y es el pie sobre el cual los Concejos de estos municipios como los estudiados, descansan sus búsquedas de ganancias en plusvalía, viendo en la "casa" el medio para acceder al mayor cobro de impuestos.

Así, este juego de poderes de los tenedores-gentrificadores y de las administraciones locales soslayan cualquier tipo de derecho para pensar estos nuevos territorios. El contenido aquí expuesto permite poner en evidencia que no se puede seguir pensando en ordenamiento territorial sin tener presentes las dinámicas y el impacto de la gentrificación rururbana, tanto a nivel conceptual como político. Esta afirmación deviene de lo que hemos encontrado en torno a lo rural y sus dinámicas contemporáneas tal como se entienden aún en los РвOT у РОТ de los municipios.

El estudio y comprensión de este fenómeno es pertinente y cobra validez en el ejercicio de la planeación y el ordenamiento
11 Para Soja (1997) un tercer territorio se concreta desde la relación entre la geograficidad, la sociabilidad y la historicidad. Sin embargo, en el presente estudio, se considera que la base de esa relación es la politica topográfica que ensambla en los procesos de gentrificación rururbana el suelo-la tierra y el territorio. tersitarios 41

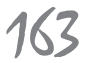


del territorio rural porque ayuda a trazar otras rutas posibles para actuar bajo un modelo que urbaniza el campo según ciertas prácticas contemporáneas. Pensar el campo colombiano solo bajo la óptica de "normalidad campesina" o de las secuelas del conflicto armado, que es fundamental, deja marginado el elemento de la gentrificación en el campo, que desde hace 30 años ha amalgamado el campo a la ciudad, sin que medie más política que verlo como una fuente de ingresos municipales que constituyen una ganancia económica pero una pérdida de entorno, de territorio en su sentido de diversidad: campo/ciudad.

Esto hace perentoria una planificación territorial donde quepa lo rururbano a la luz de las nuevas dinámicas territoriales como las aquí expuestas, para abrir paso a unas políticas incluyentes de este tipo de territorialidades contemporáneas en el medio rural.

En estas territorialidades contemporáneas (Velásquez, 2015; Linck, 2000; Pérez, 2001; Llambí, 2012; Hiernaux, 2001 ; Ávila, 2005; Arias, 2002; Jiménez, 2012; González, 2013, González Plazas, 2008) es evidente la intersección manifiesta entre la historia del campo, hoy con una fuerte expansión de la sociedad urbana dominante (Gavignaud, 1990), el campo como un cuadro de vida antes que un lugar de producción (Hervieu, 1979) y la bifurcación económica (Bradshaw, 1993 ) puesta en el peso de la transacción de oferta y demanda de tierra, que se vive en La Florida y Cerritos como un reflejo de este fenómeno global.
Lo que marca la gentrificación rururbana, tal como lo hemos mostrado, es sobre todo el aumento en el precio del suelo, el impacto residencial y las infografías o marcas fisiográficas y sociales en el paisaje como evidencia de una brusca y no planificada transformación territorial. Esto, además de los impactos ya vistos, genera como consecuencia no intencional de un acto intencional, nuevas centralidades debido a la instalación e incremento de urbanitas en zonas rururbanas y como dice Gerber (2000) a su dinamismo económico; es decir, a todas luces un tercer territorio, que surge y crece a la manera de una casa donde aumentan los cuartos, sin mediar la mínima exigencia de ordenamiento territorial. Ese retorno al campo para gozar de sus bondades en medio de las presiones ambientales, de infraestructura y del desmedido uso del suelo para construir viviendas puede convertir a La Florida y a Cerritos en "un bosque sin encanto" donde la política pública de la ordenación del territorio no sea más que un medio para medir impuestos y superponer territorios a la manera de una exaptación territorial, cuya evolución provee en principio adaptación a todos los nuevos allegados (habitantes, empresarios, etc.) con las condiciones existentes, pero que comienzan a ser gestionados con lógicas que pueden superar el principio originario de "buscar y encontrar la naturaleza", para convertirse en una tensa cohabitación, que aleja a la gentrificación rururbana del propósito con la que fue creada. Todo lo cual generaría una "tierra para nadie": ni para 
los nativos, que ya casi son inexistentes, ni para los allegados urbanitas.

\section{Referencias}

Acosta-Nates, P. (2009). Transformaciones territoriales y reconfiguración de los espacios rurales: una aproximación antropológica a la gentrificación en la vereda Clarete, municipio de Popayán Cauca. Popayán: Universidad del Cauca.

Andreani, J. L. ( 7 de mayo de 1999). Quand les urbains rêvent de redevenir des ruraux. Le Monde, p. 19.

Arias, P. (2002). Hacia el espacio ruralurbano. Una revisión de la relación campo-ciudad en la antropología social mexicana. Estudios Demográficos y Urbanos, 17(2), 363-381. Doi: http:// dx.doi.org/10.24201/edu.v17i2.1142

Ávila, H. (2005). Introducción. Líneas de investigación y el debate en los estudios urbano-rurales. En H. Ávila, Lo urbanorural ¿nuevas expresiones territoriales? (pp. 19-60). Cuernavaca: CRIM-UNAM.

Ávila, H. (2009). Periurbanización y espacios rurales en la periferia de las ciudades. México: Estudios Agrarios, 15(41), 93123

Boyle, P., \& Halfacree, K. (Eds.). (1998). Migration into rural areas: theories and issues. Chichester: Wiley.

Bradshaw T. K. (1993). In the shadow of urban growth: Bifurcation in rural $\mathrm{Ca}$ lifornia communities. En A. T. Lyson \& W. W. Falk (Eds.), Forgotten places: Poor rural regions in the United States, (pp. 218-245). Kansas: University Press of Kansas.

Caldas, Alcaldía Municipal de Villamaría. Acuerdo 070, Por el cual se modifica el Plan Básico de Ordenamiento Territorial para el municipio de Villamaría (Caldas). (9 marzo 2007). Recuperado de https://villamariacaldas.micolombiadigital.gov.co/sites/villamariacaldas/content/files/000172/8562_ pbotacuerdo070.pdf

Carder. (1994). Diagnóstico ambiental de los municipios de Pereira, Dosquebradas, Marsella y Santa Rosa. Recuperado de http/diagnostico/de riesgos/ambientales/de Pereira.com

Cardoso, M. M. (2013) Atisbos de contraurbanización en la Zona Metropolitana Valle de México y en el sistema urbano nacional. Cuadernos de Geografía-Revista Colombiana de Geografía, 22(1). Recuperado de http://www. scielo.org.co/scielo.php? script $=$ sci abstract\&pid $=$ S0121-215X2013000 $100010 \& \operatorname{lng}=\mathrm{pt \& nrm}=\mathrm{iso} \& \ln \mathrm{g}=\mathrm{es}$

Castelo, C. (2007). Vidas perfectas: los countries por dentro. Buenos Aires: Sudamericana.

Concha, C., Errázuriz, T., Letelier, F., Micheletti, S., Rasse, A., \& Salcedo, R. (septiembre-octubre 2014). ¿Urbano o rural? Repensando territorios, discursos y prácticas al margen de la metrópolis. Ponencia presentada en el XXIX Congreso de la Asociación Latinoamericana de Sociología, Santiago de Chile. Recuperado de https://www.researchgate.net/publi- tersitarias 41

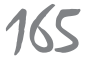


cation/273118847_Urbano_o_Rural_ Repensando_territorios_discursos_y_ practicas_al_margen_de_la_metropolis Constructora CFC\&A. (2015). Dossier de publicidad del Condominio Mocawa. La Florida Villamaria Manizales. Recuperado de http:/ /cfcconstrucciones.com. co/venta/casas-manizales-mocawa/

Correa, H. H. (1999). Villamaria y su historia Tomo I y II. Villamaría: Alcaldía de Villamaría.

DANE. (2005). Boletín censo general: perfil de Pereira, Risaralda. Recuperado de https://www.dane.gov.co/ files/censo2005/PERFIL_PDF_ CG2005/66001T7T000.PDF

En la Florida Villamaría dicen que crecen en medio de dificultades. ( 20 de diciembre de 2013). La Patria. Recuperado de http://www.lapatria.com/caldas/enla-florida-villamaria-dicen-que-crecenen-medio-de-dificultades-51175

Frediani, J., Rodríguez Tarducci, R., \& Cortizo, D. (2018). Proceso de gentrificación en áreas periféricas del partido de La Plata, Argentina. Revista del Área de Estudios Urbanos del IIGG-Facultad de Ciencias Sociales, 16(9), 9-37.

García, L. M. (2001). Elitización: propuesta en español para el término gentrificación. Revista Bibliográfica de Geografía $y$ Ciencias Sociales, 6(332).

Gavignaud G. (1990). Les campagnes en France au XX siècle (1914-1989), París: Synthèse \& Histoire, Ophrys.

tersitarios 41

Gerber P. (2000). Gentrification et confort postmoderne-Eléments émergents de nouvelles centralités -L'exemple de Stars- bourg. (Tesis de doctorado, Université de Starsbourg, Strasbourg).

Ghose, R. (1997). Cowboys and Cappuccinos: Growth, gentrification and the changing cultural landscapes of Montana. (Conference) Fort Worth, Texas: Association of American Geographers (AAG).

Giraldo Valdés. (2013). Propuesta de planificación ambiental territorial del suelo suburbano del municipio de Pereira. (Risaralda) estudio de caso. (Tesis, Universidad Autónoma de Manizales).

Glass, R. (1964). Introduction: Aspects of change in centre for urban studies. London: Editorial MacGibbon and Kee.

Gómez Agudelo, C. A., \& Arias Gómez, J. (2012). Directrices y estrategias territoriales para la consolidación de una política pública de abastecimiento alimentario para las ciudades de Villamaria y Manizales. (Tesis de maestría, Universidad de Manizales).

González Plazas, J. L. (2008). Estado actual de la Periurbanización y el hábitat periurbano en Manizales (Colombia). Cuadernos de Vivienda y Urbanismo, 2, 93-122. Recuperado de http:// journaldatabase.info/articles/estado_actual_periurbanizacion_y_el.html

González Rojas, N. (2013). Transformación del espacio rural a urbano: análisis sobre la influencia de la desruralización en la interacción de los primeros habitantes de Suba. Traza, (8), 88-104.
Guimond, L., \& Simard, M. (2010). Gentrification and neo-rural populations in the Quebec countryside: representa- 
tions of various actors. Journal of Rural Studies, 26(4), 449. Doi: https://doi. org/10.1016/j.jrurstud.2010.06.002 Hernández Flores, J. A., Martínez Corona, B., \& Méndez Espinoza, J. A. (2014). Reconfiguración territorial y estrategias de reproducción social en el periurbano poblano. Cuadernos de Desarrollo Rural, 11(74), 13-34. Doi: http://dx.doi. org/10.11144/Javeriana.CRD11-74. rter

Hervieu B., L. D. (1979). Le retour à la nature: au fond de la forêt... l'Etat. París: Seuil.

Hierneaux, D. (2001). Las nuevas formas urbanas y reestructuración del mundo rural. En P. Torres (Comp.), Procesos metropolitanos y agricultura urbana, (pp. 31-41). México D. F.: Universidad Autónoma Metropolitana-Organización de las Naciones Unidas para la Agricultura y la Alimentación.

Hincapié, E., \& Valencia, J. (2011). Plan de manejo ambiental para la conservación del bosque seco tropical en el proyecto "Palo Alto" al occidente de Cerritos, Pereira. (Tesis de pregrado, Universidad Tecnológica de Pereira, Colombia).

Inzulza, J., \& Galleguillos, X. (2014). Latino gentrificación y polarización: transformaciones socioespaciales en barrios pericentrales y periféricos de Santiago de Chile. Revista de Geografía Norte Grande, (58), 135-159. Recuperado de http://repositorio.uchile.cl/handle $/ 2250 / 132599$

Janoschka, M. (2016) Gentrificación, desplazamiento, desposesión: procesos urbanos claves en América Latina. Revista INVI, 3I(88), 27-71.

Janoschkaa, M., \& Salinas Arreortua, L. (2017). Peripheral urbanisation in Mexico City. A comparative analysis of uneven social and material geographies in low-income housing estates. Habitat International. 70, 43-49.

Jiménez, L. C. (2012). Crecimiento urbano "patrones del crecimiento en Colombia”. Bogotá: Universidad Nacional de Colombia.

Linck, T. (agosto 2000). El campo en la ciudad: reflexiones en torno a las ruralidadesemergentes. Ponencia Presentada en el Seminario Internacional. La Nueva Ruralidad en América Latina, Pontificia Universidad Javeriana, Bogotá, Colombia.

Llambí, L. (2012). Procesos de transformación de los territorios rurales latinoamericanos: los retos de la interdisciplinariedad. Eutopía. Relación Campo Ciudad. Revista de Desarrollo Económico Territorial, (3), 117-134. Doi: https://doi. org/10.17141/eutopia.3.2011.1022

Lorenzen Martiny, M. J. (2015). ¿La gentrificación rural y urbana como factor de anclaje de la población originaria? Indicios desde Morelos, México. En V. Deñgadillo, I. Díaz \& L. Salinas (Coords.), Perspectivas del estudio de la gentrificación en México y América Latina (pp. 277-300). México D. F.: UNAM-Instituto de Geografía.

Macuacé, R. A., \& Gómez, A. M. (2014). Migración hacia los espacios rururbanos en Popayán (Colombia) para la territarias 41

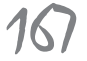


primera década del siglo XXI. Revista de Economía del caribe, (14). Recuperado de http://rcientificas.uninorte. edu.co/index.php/economia/article/ view $/ 6347 / 6567$

Manizales, Alcaldía. (2013). Acuerdo constitución áreas metropolitanas.

Malizia, M. (2011). Countries y barrios privados en el Gran San Miguel de Tucumán. Efectos y contrastes sociales. (Tesis de doctorado, Universidad Nacional de Tucumán, Argentina).

Martínez, E. (2006). Nueva relación ruralurbana: globalización y transformaciones socio-espaciales en Los Altos de Morelos, México. Ponencia presentada en el VII Congreso de la Asociación Latinoamericana de Sociología Rural, Quito: Alasru.

Martí-Costa, M., Durán, G., \& Marulanda, A. (2016). Entre la movilidad social y el desplazamiento. Una aproximación cuantitativa a la gentrificación en Quito. Revista INVI, 31(88), 131-160.

Marulanda. G. (2014). Aproximación a la instrumentación de un modelo de intervención y ordenamiento territorial para el suelo suburbano en el municipio de Pereira. (Tesis de maestría, Universidad Nacional de Colombia, Manizales, Colombia).

Milano, C. (2016). Campesinos y pescadores ante la promoción del turismo residencial en el Delta del Parnaíba (Brasil). Revista de Turismo y Patrimonio Cultural, (16), 61-80.

Nates-Cruz, B., \& Raymond, S. (2007). Buscando la naturaleza. Migración $y$ dinámicas rurales contemporáneas. Barcelona: Editorial Anthropos.

Nates-Cruz, B. (2009). Procesos de gentrificación en lugares rururbanos: presupuestos conceptuales para su estudio en Colombia. Revista Virajes, (10), 253-269.

Nates-Cruz, B. (2017). Los lugares, el lugar de la antropología del territorio en Colombia. En J. Tocancipá Falla (Comp.), Antropologias en Colombia: tendencias y debates actuales (pp. 393447). Popayán: Universidad del Cauca.

Nates-Cruz, B. (2018). The rururban and the contemporary rururbanity. Crosssectional analysis from Latin America. En M. Luckas \& N. Reis (Eds.), Beyond the mega-city: New dimensions of peripheral urbanization in Latin America (en prensa a consultar en noviembre 2018).

Osorio, Y., \& Silva, C. (2007). Caracterización del mercado inmobiliario en el municipio de Pereira en el periodo 20062007. Pereira: Editorial Universidad Tecnológica de Pereira.

Parra Carrasco, N. (2016). ¿ Gentrificación rururbana? Exploración de los procesos de transformación y conformación residencial de Maule norte. (Tesis de maestría, Universidad de Chile).

Pereira, Alcaldía. (2007). Plan de Desarrollo del Corregimiento de Cerritos. Cerritos Progresando. 2007-2016.

Pereira, Alcaldía. (2011). Contexto socioeconómico de Pereira. Cartagena: Banco de la República. 
Pereira, Alcaldía Municipal. Plan de Ordenamiento Territorial de Pereira Risaralda (mayo 19, 2000).

Pereira, Concejo Municipal. Acuerdo Municipal 23 "Por el cual se adopta la revisión del plan del ordenamiento territorial del Municipio de Pereira" (julio 23, 2006).

Pérez, E. (2001). Hacia una nueva visión de lo ruralidad. En N. Giarraca (Comp.), ¿Una nueva ruralidad en América Latina? (17-29). Buenos Aires: Clacso.

Perrier-Cornet, P. (Dir.). (2002). Repenser les campagnes. París: Datar/Edition de l'Aube.

Piñeiro, C. (2005). Las viudas de los jueves. Buenos Aires: Editorial Alfaguara.

Phillips, M. (1993). Rural gentrification and the processes of class colonization. Journal of Rural Studies, (2), 123-140. Doi: 10.1016/0743-0167(93)90026G

Phillips, M. (julio 2000). Making space for ruralgentrification. Ponencia presentada en el II Simposio Anglo-Español de Geografía Rural, Universidad de Valladolid, España.

Phillips, M., \& Smith, D. P. (2018). Comparative approaches to gentrification. Lessons from the rural. Dialogues in Human Geography, 8(1), 3-25. Doi: https://doi. org/10.1177/2043820617752009

de Quéiroz Ribeiro, L.C. (2004). Metrópoles: entre a coesão e afragmentação, a cooperação e o conflito. São Paulo: Fundação Perseu Abramo.
Raymond, S. (1994). Articulations des initiatives non agricoles, publiques et privées, individuelles et collectives, dans les zones rurales fragiles, DEA. (Tesis de maestría, Université Toulouse II).

Raymond, S. (2003). Du "retour à la nature» au «retour à la campagne». Migrants et recompositions territoriales dans le Midi de la France et en Californie du Nord. (Tesis de doctorado, Université de Toulouse Le Mirail, Toulouse, Fracia). Richard F. (2009). La gentrification des «espaces naturels» en Angleterre: après le front écologique, l'occupation? L'Espace Politique, 9. Doi: 10.4000/ espacepolitique. 1478

Rojas, P. (2007). Mundo privado: historias de vida en countries, barrios y ciudades cerradas. Buenos Aires: Planeta.

Sabatini, F., Sarella, M., \& Vásquez, H. (2008). Gentrificación sin expulsión, o la ciudad latinoamericana en una encrucijada histórica. Arquitectura, Arte y Diseño, 180(24).

Sabatini, F. (2015). Transformación de la periferia urbana popular: entre el estigma y la devolución espacial. En A. Lindón \& C. Mendoza (Ed.) La periferia metropolitana: entre la ciudad prometida y un lugar para habitar la Ciudad de México (57-91). México: Gedisa y Universidad Autónoma Metropolitana Iztapalapa.

Salazar, S. (15 de abril de 2012). Villamaría no para de crecer hacia La Florida. La Patria. Recuperado de http://www. 
lapatria.com/caldas/villamaria-nopara-de-crecer-hacia-la-florida-3077

Simard, M., \& Guimond, L. (2012). Que penser de l'embourgeoisement rural au Québec? Visions différenciées d'acteurs locaux. Recherches sociographiques, 53(3), 527-553.

Simard, M., \& Guimond, L. (2013). Des «étrangers» parmi nous? Représentations et pratiques de divers acteurs ruraux face à l'installation de nouvelles populations dans les campagnes au Québec. Géographie, Économie, Société, 15(1), 25-46.

Smith N. (1996). The New Urban Frontier: Gentrification and the Revanchist City. London and New York: Routledge.

Soja, E. (1997). El tercer espacio. Ampliando el horizonte de la imaginación geográfica. Geográfikos, 8, 71-76.

Svampa, M. (2008). Los que ganaron: la vida en los countries y barrios privados. Buenos Aires: Biblos.

Traslaviña Rodriguez, E (2016). Gentrificación rural: estudio de caso en la vereda Aguas Claras del municipio de El Carmen de Viboral - Antioquia. (Tesis de maestría, Universidad Nacional de Colombia, Medellín, Colombia).

Urzúa, K. E. (2013). ¿Gentrificación contemporánea en contexto urbano-rural chileno? El caso de los condominios cerrados de las comunas del Alto
Aconcagua. (Tesis de maestría, Universidad de Chile, Santiago de Chile). Velásquez, P. (2015). Territorializaciones rurales contemporáneas. (Tesis de doctorado, Universidad de Caldas, Manizales). Villamaría, Alcaldía. (2000). Plan Básico de Ordenamiento Territorial de Villamaría Caldas.

Villamaría, Alcaldía (2009). Plan Básico de Ordenamiento Territorial de Villamaría Caldas. Recuperado de http:// cdim.esap.edu.co/bancomedios/ documentos $\% 20 \mathrm{pdf} /$ pot-villamariacaldas-2004-2009-proyecto $\% 20 \mathrm{de} \% 20$ acuerdo-(139\%20pág\%20-\%20524\%20 $\mathrm{kb}) \cdot \mathrm{pdf}$

Villamaría, Secretaría de Planeación. (2012). Cartografía municipal.

Villamaría, Secretaría de Planeación. Plan de Desarrollo 2012-2015. Recuperado de http://cdim.esap.edu.co/BancoMedios/Documentos\%20PDF/villamariapd-\%202012_2015.pdf

"Villamaría se está convirtiendo en una gran ciudad": alcalde. (26 de junio de 2013). La Patria. Recuperado de http://www.lapatria.com/caldas / villamaria-se-esta-convirtiendo-en-unagran-ciudad-alcalde-37006

Zuluaga, G. P. (2005). Dinámicas territoriales en frontera rural-urbana en corregimiento de Santa Elena, Medellín. (Tesis de maestría, Universidad Nacional de Colombia, Medellín, Colombia). 